\title{
Mixing Properties and Gluten Yield of Dough Enriched with Pea Protein Isolates
}

\author{
Samuel Mercier, Sébastien Villeneuve (Corresponding author), Martin Mondor, Hélène Drolet, Denis \\ Ippersiel, François Lamarche \& Louis-Philippe Des Marchais \\ Food Research and Development Centre \\ Agriculture and Agri-Food Canada \\ 3600 Casavant Blvd West, Saint-Hyacinthe \\ Quebec J2S 8E3, Canada
}

Tel: 1-450-768-3335_E-mail: sebastien.villeneuve@agr.gc.ca

Received: November 9, $2011 \quad$ Accepted: December 2, $2011 \quad$ Published: February 1, 2012

doi:10.5539/jfr.v1n1p13 URL: http://dx.doi.org/10.5539/jfr.v1n1p13

The research was financed by Agriculture and Agri-Food Canada.

\begin{abstract}
Over the last few years, many studies were carried out on the use of legume-based ingredients to supplement cereal-based matrices and produce nutritionally enhanced products. However, little is known about the influence of supplementation on the mixing properties of the enriched cereal-based matrices. The objective of this work was to study the impact of supplementing cereal-based matrices with commercial pea protein isolate or pea protein isolate produced by ultrafiltration/diafiltration using a $50 \mathrm{kDa}$ membrane on the dough mixing properties. Studies were performed using a Perten ${ }^{\circledR}$ Glutomatic to estimate gluten yield, namely in terms of gluten index, wet gluten, dry gluten and water binding capacity, and using a Brabender ${ }^{\circledR}$ Farinograph to estimate water absorption, dough development time, stability, mixing tolerance index and minimum and maximum water content for dough formation. Four levels of pea protein isolate enrichment were considered: $0,5,10$ and $15 \%$. Results indicated that level of enrichment has little effect on measured mixing properties compared to the pea protein isolates considered. Isolate processed by membrane technologies takes part to the dough formation which does not seem to be the case with commercial isolate. Higher amount of water is required for dough formation with matrices enriched with commercial pea isolate compared to membrane processed isolate, while stronger dough properties are observed for matrices enriched with membrane processed isolate. This is attributable to the properties of the isolate, namely solubility and state of the proteins (native or denatured), which could impact how they interact with wheat proteins.
\end{abstract}

Keywords: Farinograph, Glutomatic, Mixing properties, Gluten yield, Pea protein, Durum wheat semolina

\section{Introduction}

Over the last few years, many studies were carried out on the use of legume based products to supplement durum wheat semolina and produce nutritionally enhanced pasta (Nielsen, Sumner \& Whalley, 1980; Bahnassey, Khan \& Harrold, 1986; Yanez-Farias, Bernal-Aguilar, Ramirez-Rodriguez \& Barron-Hoyos, 1999; Zhao, Manthey, Chang, Hou \& Yuan, 2005; Sabanis, Makri \& Doxastakis, 2006; Shogren, Hareland \& Wu, 2006; Torres, Frias, Granito, Guerra \& Vidal-Valverde, 2007; Wood, 2009; Gallegos-Infante, Rocha-Guzman, Gonzalez-Laredo, Ochoa-Martinez, Corzo, Bello-Perez, Medina-Torres \& Peralta-Alvarez, 2010; Petitot, Boyer, Minier \& Micard, 2010; Mercier, Villeneuve, Mondor \& Des Marchais, 2011). Supplementation with legume protein ingredients allows to improve pasta protein content and compensates wheat semolina deficiency in lysine and threonine, two essential amino acids (Kies \& Fox, 1970; Abdel-Aal \& Hucl, 2002; Sánchez-Lozano \& Martínez-Llorens, 2009).

It was observed that enrichment affects pasta quality, namely in terms of texture (Nielsen et al., 1980), color (Gallegos-Infante et al., 2010), cooking quality (Zhao et al., 2005), sensorial aspect (Alireza Sadeghi \& Bhagya, 2008) and engineering properties (Mercier et al. 2011). The impact of fortification is dependant on the level of supplementation and on the legume from which origins the product (Zhao et al., 2005; Petitot et al., 2010). 
However, little is known about the influence of the processing of the protein ingredients. Indeed, these ingredients can be made using various processes which can influence proteins structure and as a result the proteins functional properties including their solubility. For example, it is well known that soy protein isolate produced by isoelectric precipitation are more denatured and as a result have lower solubility than isolates produced by membrane technologies (Petruccelli \& Anon, 1994; Wagner, Sorgentini \& Anon, 2000; Rao, Shallo, Ericson, \& Thomas, 2002). As observed by Ribotta, Edel Leon, Pérez \& Anon (2005) in the case of soy proteins, the state of the proteins (native or denaturated) can impact their solubility and therefore their interaction with wheat proteins.

The objective of this work was to study the impact of supplementing cereal-based matrices with commercial pea protein isolate or pea protein isolate produced by ultrafiltration/diafiltration using a $50 \mathrm{kDa}$ membrane. Effect of enrichment was studied on dough mixing properties and gluten yield, which are properties that are highly correlated to the final product quality, namely in terms of texture and cooking characteristics (Dexter \& Matsuo, 1980; Ohm \& Chung, 1999; Mason, Navabi, Frick, O’Donovan, Niziol, \& Spaner, 2006; Oak, Sissons, Egan, Tamhankar, Rao \& Bhosale, 2006).

\section{Materials and Methods}

\subsection{Raw materials}

Commercial pea protein isolate (CPPI) was purchased from Nutri-pea Limited (Portage La Prairie, MB, Canada). Isolate produced by membrane technologies (MTPPI) was made from certified \#1 Eclipse Yellow peas purchased from Wagon Wheel Seed Corporation (Churchbridge, SK, Canada). Roller-milled durum wheat semolina was purchased from Horizon Milling (Montreal, QC, Canada).

\subsection{Production of pea protein isolate by membrane technologies}

Pea protein isolate was produced by membrane technologies as previously described by Taherian et al. (2011). The peas were first soaked in water (ratio $1: 8 \mathrm{w} / \mathrm{w}$ ) at room temperature for 90 minutes to swell them and detach the grain hull or cuticle so they would be easier to dehull afterwards. After soaking for 90 minutes in water, sodium hypochlorite $(\mathrm{NaOCl})$ was added to the mixture until a concentration of $0.7 \mathrm{~g} / \mathrm{L}$ was reached and the soaking was carried out for an additional 30 minutes. The peas were then recuperated and rinsed with water (ratio $1: 8 \mathrm{w} / \mathrm{w}$ ) to remove any residual sodium hypochlorite. They were dried overnight in a forced air 4-plate dryer (The National Drying Machinery Co., Philadelphia, Pennsylvania, USA, model 52979) operated at room temperature. Upon removal from the oven, the peas were ground using a Quadro Comil model 196 (Quadro Engineering Inc., Ontario, Canada) equipped with screen 002 for a first pass and with screen 009 for a second pass. The broken peas and their hulls were then passed through a multi aspirator (Kice, Wichita, Kansas, USA, model 6F6), where the hulls were removed from the top while the dehulled peas fell into the reservoir through the force of gravity. The dehulled peas were ground again using the Quadro Comil equipped with screen 106 to produce flour. The flour was placed in aluminium pouches which were hermetically sealed and stored at $4{ }^{\circ} \mathrm{C}$ until used.

For the production of the pea protein isolate, $7 \mathrm{~kg}$ of flour was dispersed in $105 \mathrm{~kg}$ of water (ratio $1: 15 \mathrm{w} / \mathrm{w}$ ) at room temperature and the dispersion was agitated for 30 minutes to allow the hydration of the flour. The $\mathrm{pH}$ of the dispersion was then adjusted to 7.5 using $2 \mathrm{M} \mathrm{NaOH}$ and the extraction was carried out for 45 minutes under agitation. If required, the $\mathrm{pH}$ was readjusted during the extraction. Once the extraction was completed, the insoluble matter was removed using a Basket Centrifuge (Western States, Hamilton, Ohio, USA, model STM-1000). In a first pass, a filter bag with a molecular weight cut-off of $60 \mu \mathrm{m}$ was used while in a second pass, a filter bag with a molecular weight cut-off of $1 \mu \mathrm{m}$ was used. The solution obtained after removal of the insoluble matter was then purified by ultrafiltration/diafiltration (UF/DF) using an home-made module equipped with two $50 \mathrm{kDa}$ hollow fibre membranes with a surface of $2.3 \mathrm{~m}^{2}$ for each membrane (Romicon (KOCH) model CTG 3", HF 25-60-PM50). The UF/DF sequence used to purify the pea extract was a UF step with a VCR 5 carried out at the extraction $\mathrm{pH}$ (i.e. 7.5) and a discontinuous DF step with a re-VCR 5 again at the extraction $\mathrm{pH}$. The resulting pea protein isolate was lyophilized and placed in aluminium pouches which were hermetically sealed in stored at $4{ }^{\circ} \mathrm{C}$ until used.

\subsection{Solubility of pea protein isolates}

Protein solubility of both isolates was determined at $\mathrm{pH} 7$ as follows: dry samples were rehydrated in bi-distilled water in order to obtain a $5 \% \mathrm{w} / \mathrm{w}$ solution ( $1 \mathrm{~g}$ of isolates in $19 \mathrm{~g}$ of bi-distilled water). The solutions were vigorously agitated for a few seconds using a vortex mixer and allowed to rest at room temperature for approximately two hours, with a second agitation after one hour. The samples were then centrifuged at $4000 \mathrm{~g}$ 
for 15 minutes at room temperature. An aliquot of approximately $5 \mathrm{ml}$ of the supernatant was taken, weighed with precision, and transferred to a Kjeldahl flask. Supernatant samples were mineralized and then titrated in the Kjeldahl flask, an official method for proteins determination. Protein relative solubility was determined by multiplying the fraction of protein in the supernatant over total protein content (dry basis) by 100. Moisture content was determined using AOAC Methods 925.09 (AOAC International, 1995) by drying samples overnight in a vacuum oven at $92{ }^{\circ} \mathrm{C}$.

\subsection{Farinograph analysis}

Farinograph analysis was performed using two methods. The first method was the classical constant dough weight AACC Approved Method 54-21.02. This method measures and records the resistance of dough to mixing. It is used to evaluate the absorption of flours and to determine stability and other characteristics of dough during mixing. Results were expressed in terms of 6 parameters: (1) water absorption, which is the amount of water required to bring the dough to $500 \mathrm{FU}$; (2) dough development time, which is the time from water addition to the first sign of dough weakening in the range of maximum consistency; (3) stability, which is the difference in time between the points where the top of the curve reach and leave a constant torque line tangent to the middle curve at the point of maximum consistency; (4) mixing tolerance index, which corresponds to the decrease in Farinograph units (FU) between the top of the curve at maximum consistency and the top of the curve four minutes after maximum consistency was reached; (5) overmixing tolerance index, defined here as the decrease in FU between the top of the curve four and eight minutes after maximum consistency was reached; (6) bandwidth, which is the difference in torque between the top and bottom line as measured four minutes after peak time.

The second Farinograph method was a modified version of the continuous water addition method developed by Landillon, Cassan, Morel \& Cuq (2008). Water was continuously added to the dough at a rate of $4 \mathrm{~mL} \mathrm{~min}^{-1}$ with a Masterflex peristaltic pump. Results were expressed as resistance to mixing (in FU) versus dough water content. Three parameters were determined: (1) minimum water content for dough formation, which was arbitrarily defined as dough water content when a $100 \mathrm{FU}$ torque level was reached; (2) water content at maximum torque, which corresponds to dough water content at maximum torque; (3) maximum torque, which was the highest value of FU reached.

Both methods were conducted using a Brabender-E Farinograph equipped with a 50-g bowl (Model FA-R/2; Brabender Co., South Hackensack, NJ, USA). All Farinograph tests were conducted in duplicate with durum wheat semolina substituted at a 5,10 and 15\% level with CPPI and MTPPI.

\subsection{Gluten yield}

Gluten yield analysis was performed according to AACC Approved Method 38-12.02 using a Glutomatic (Perten Instruments, Huddinge, Sweden). Results were expressed in terms of gluten index, wet gluten, dry gluten and water binding capacity. Tests were conducted in triplicate with durum wheat semolina substituted at a $0,5,10$ and $15 \%$ level with CPPI and MTPPI.

\subsection{Statistical analysis}

Analysis of variance was performed a priori on each parameter using SAS software (version 8.2, SAS Institute Inc.. Cary, NC, USA). Multiple comparison procedures (Least Significant Difference, $p=0.05$ ) were performed a posteriori to compare parameters whose variance was significantly different.

\section{Results}

\subsection{Pea isolates protein content and solubility}

The protein content of the CPPI is $84.8 \pm 0.4 \%$ dry basis, which is lower than the protein content of the MTPPI ( $96.1 \pm 0.2 \%$ dry basis). However, the solubility of the CPPI is $6.1 \pm 0.2 \%$, which is approximately 13.8 times lower than the one of the MTPPI $(85.1 \pm 0.8 \%)$. This indicates that MTPPI proteins are mostly in their native states, while CPPI proteins are denatured.

\subsection{Mixing properties}

Typical data obtained using the Farinograph constant dough weight method, with $10 \%$ enrichment level, are presented in Figure 1. Dough with substituted CPPI showed a characteristic sharp peak and noise around dough development time (indicated by the vertical line below the curve), while data of dough containing MTPPI were smoother, without sharp peak. This suggests that the protein solubility has a more important impact on dough formation than the protein content of the isolates since the behaviour (shape of the curve in Figure 1) was strongly affected. It is well known that difference in protein content alone would not have affected the shape of the curve but only the intensity of the various parameters (Irvine, Bradley \& Martin, 1961). 
Measured Farinograph parameters are presented in Figure 2-7. Increasing durum wheat substitution level with both CPPI and MTPPI resulted in higher water absorption (Figure 2) compared to control $(\mathrm{P}<0.01)$. This is the trend typically observed when flour or semolina is enriched with proteins (Wood, 2009; Sabanis et al., 2006; Mashayekh, Mahmoodi \& Entezari, 2008). Although MTPPI had higher protein content, it overall resulted in dough with lower water absorption than CPPI at an enrichment level of $15 \%(\mathrm{P}<0.05)$, but not at 5 or $10 \%$ level.

Dough development time (Figure 3) increased when CPPI or MTPPI was added to semolina $(\mathrm{P}<0.01)$, but only at $5 \%$ substitution level, which is similar to the results reported by Ribotta et al. (2005) with soybean flour. However, the gluten network may not have been completely formed at the measured dough development time for semolina enriched with high level of CPPI. Indeed, curves were very unstable and wide around this point and another small increase in consistency was observed 3-5 min after dough development time for $15 \%$ CPPI enrichment level.

Enriching semolina with CPPI at a 5\% level induced a sharp increase in stability (Figure 4) and a diminution of mixing tolerance index (Figure 5) compared to control $(\mathrm{P}<0.05)$. Both of those properties are associated to strong flour or semolina. However, a reverse trend was observed at 10 and $15 \%$ enrichment level. Indeed, the Farinograph curves for 10 and 15\% CPPI level showed just as good stability in the long run after the peak compared to $5 \%$. This is supported by the decrease in overmixing tolerance index (Figure 6) for 10 or $15 \%$ CPPI level compared to control $(\mathrm{P}<0.05)$. The opposite was observed with the MTPPI: overmixing tolerance index was higher than control when a substitution level of $15 \%$ was used $(\mathrm{P}<0.05)$.

Dexter and Matsuo (1980) reported that bandwidth correlates well with gluten strength and spaghetti cooking and overcooking quality. Their results indicated that wide bandwidth is linked to strong gluten with good cooking and overcooking qualities. In this study, enrichment with both isolates resulted in lower bandwidth $(\mathrm{P}<$ 0.05) than control (Figure 7), which might be due to gluten dilution. Decline in bandwidth was more pronounced with MTPPI compared to CPPI $(\mathrm{P}<0.05)$.

Dough mixing properties under continuous water addition are presented in Table 1. While the classical Farinograph method allows analysing dough resistance to mixing over time, this procedure allows to study the behaviour of dough at different moisture content. Minimum water content for dough formation was affected by the isolate $(\mathrm{P}<0.01)$. MTPPI supplementation caused a decrease of this parameter compared to CPPI or to isolate-free semolina. This effect was enhanced at 10 or $15 \%$ enrichment level $(\mathrm{P}<0.01)$. This indicates that semolina enriched with MTPPI requires less water for the development of the gluten network. Petitot et al. (2010) also reported a decrease in minimum water content for dough formation with durum wheat flour enriched with split pea of faba bean flour.

Similar results were obtained for dough water content at maximum torque. Enrichment with MTPPI resulted in a decrease in water content at maximum torque compared to control $(\mathrm{P}<0.05)$, while enrichment with CPPI did not have a significant effect. The decrease in water content at maximum torque with MTPPI was independent of the level of substitution.

In terms of the maximum torque obtained, effects were observed for both the type of isolate and substitution level $(\mathrm{P}<0.01)$. The addition of isolate resulted in dough with higher resistance to mixing at the water content of maximum torque, especially in the case of MTPPI.

\subsection{Gluten yield}

Parameters from gluten yield experiments are presented in Table 2. No results are available for CPPI at a $15 \%$ enrichment level because no gluten network developed during the mixing step in the Glutomatic. Similar observations were made by Ribotta et al. (2005) with durum wheat flour enriched with soy protein flour. However, a gluten network developed for each substitution level when using MTPPI. This indicates that the CPPI is more harmful to gluten formation than MTPPI especially at higher level of supplementation.

Gluten index represents the ratio of strong gluten to total gluten. Matsuo, Dexter, Kosmolak \& Leisle (1982) and D'Egidio, Mariani, Nardi, Novaro \& Cubadda (1990) indicated that gluten strength is an important factor influencing pasta quality. In the present study, gluten index was significantly influenced by the protein isolate ( $\mathrm{P}$ $<0.01$ ). Overall, gluten was stronger when semolina was enriched with MTPPI compared to control or dough enriched with CPPI. This effect was independent of the level of substitution. This result is due to the fact that proteins of the MTPPI have more interactions with the gluten proteins compared to CPPI, causing more important changes in the network properties.

Wet and dried gluten, when measured in terms of percentage of dry wheat semolina, were influenced by both the 
type of isolate and substitution level $(\mathrm{P}<0.01)$. Less gluten was retrieved when semolina was enriched with the MTPPI compared to CPPI or isolate-free semolina. Moreover, the difference was enhanced with high MTPPI substitution level. Thus, MTPPI retrieves some gluten from the network, causing it to pass through the Glutomatic screen with water and starch, which is not the case or at lesser extent for CPPI.

Water binding capacity, when expressed in terms of percentage of wet gluten, was not affected by the protein isolate or enrichment level. Thus, enriching semolina with pea proteins did not affect gluten capacity to hold water.

\section{Discussion of the Impact of Supplementing Durum Wheat Semolina with Pea Protein Isolate}

Enriching durum wheat semolina with protein isolate altered most dough properties as measured by Farinograph and Glutomatic. However, the impact was dependant on which isolate was used. Enrichment with CPPI did not impact gluten development, the minimum water content for dough formation and the water content at maximum torque while it increased the maximum torque. Enrichment with MTPPI resulted in an increase in gluten strength, and decreases in wet and dry gluten. It also required less water for the development of the network while it increased the maximum torque. In practice, these observations suggest that the MTPPI will take part to the network formation of pasta matrices while the CPPI would remain entrapped into the network limiting the amount of CPPI that can be supplemented into the pasta. In this context, previous work on the bread-making potential of the MTPPI clearly showed that bread matrix can support $10 \%$ substitution with MTPPI without harmful effect on the network (Des Marchais, Foisy, Mercier, Villeneuve, \& Mondor, 2011). This resulted in bread with $20.9 \pm 0.1 \%$ of protein which can be considered as high protein bread.

The impact of the two protein isolates is different due to the conformation state in which their proteins are. MTPPI making process leads to soluble proteins, while CPPI proteins were very less soluble. This indicates that the proteins presents in the MTPPI are less denatured than the ones in the CPPI. This impacts how pea and gluten proteins interact, similarly to what is observed in the case of wheat-soy protein interactions (Ribotta et al., 2005; Roccia, Ribotta, Pérez \& Leon, 2009). Pea proteins in their native state interact more directly with wheat proteins, thus explaining the increase in maximum torque and gluten index observed with MTPPI. Moreover, decreases in wet gluten and dry gluten are due to wheat-pea proteins interactions causing an increase in gluten solubility. On the contrary, proteins from CPPI alter dough properties more indirectly because of water competition and gluten dilution. To strengthen these observations, it would be of interest to perform some chemical analysis on the dough during its formation in order to assess the nature of the interactions between proteins. For example, the quantitative measurements of sulfhydryl (SH) and disulfide (SS) bonds would be of interest.

\section{Conclusion}

Level of dough enrichment with pea protein isolates $(0,5,10$ and $15 \%)$ has little effect on measured mixing properties compared to the pea protein isolate considered for enrichment. Pea protein isolate processed by membrane technologies takes part to the dough formation, which does not seem to be the case with commercial isolate. Higher amount of water is required for dough formation with matrices enriched with commercial pea isolate compared to membrane processed isolate or isolate-free dough, while stronger dough properties are observed for matrices enriched with membrane processed isolate.

\section{References}

Abdel-Aal, E. S. M., \& Hucl, P. (2002). Amino Acid Composition and In Vitro Protein Digestibility of Selected Ancient Wheats and their End Products. Journal of Food Composition and Analysis. 15(6), 737-747. http://dx.doi.org/10.1006/jfca.2002.1094

Alireza Sadeghi, M., \& Bhagya, S. (2008). Quality Characterization of Pasta Enriched with Mustard Protein Isolate. Journal of Food Science. 73(5), S229-S237. http://dx.doi.org/10.1111/j.1750-3841.2008.00742.x

Bahnassey, Y., Khan, K., \& Harrold, R. (1986). Fortification of spaghetti with edible legumes. 1. Physicochemical, antinutritional, amino acid, and mineral composition. Cereal chemistry. 63, 210-215.

D’Egidio, M. G., Mariani, B. M., Nardi, S., Novaro, P., \& Cubadda, R. (1990). Chemical and technological variables and their relationships: A predictive equation for pasta cooking quality. Cereal Chemistry, 67, 275-281.

Des Marchais, L. P., Foisy, M., Mercier, S., Villeneuve, S., \& Mondor, M. (2011), Bread-making potential of pea protein isolate produced by a novel ultrafiltration/diafiltration process, 11th International Congress on Engineering and Food (ICEF11), Procedia - Food Science. 1, 1425-1430. http://dx.doi.org/10.1016/j.profoo.2011.09.211 
Dexter, J. E., \& Matsuo, R. R. (1982). Relationship between Durum Wheat Protein Properties and Pasta Dough Rheology and Spaghetti Cooking Quality. Journal of Agricultural and Food Chemistry. 28, 899-902. http://dx.doi.org/10.1021/jf60231a034

Gallegos-Infante, J. A., Rocha-Guzman, N. E., Gonzalez-Laredo, R. F., Ochoa-Martinez, L. A., Corzo, N., Bello-Perez, L. A., Medina-Torres, L., \& Peralta-Alvarez, L. E. (2010). Quality of spaghetti pasta containing Mexican common bean flour (Phaseolus vulgaris L.). Food Chemistry. 119(4), 1544-1549. http://dx.doi.org/10.1016/j.foodchem.2009.09.040

Irvine, G. N., Bradley, J. W., \& Martin, G. C. (1961). A farinograph technique for macaroni dough. Cereal Chemistry, 38, 153-164.

Kies, C., \& Fox, H. M. (1970). Determination of the first-limiting amino acid of wheat and triticale grain for humans. Cereal Chemistry, 47, 615-622.

Landillon, V., Cassan, D., Morel, M. H., \& Cuq, B. (2008). Flowability, cohesive, and granulation properties of wheat powders. Journal of Food Engineering, 86, 178-193. http://dx.doi.org/10.1016/j.jfoodeng.2007.09.022

Mashayekh, M., Mahmoodi, M. R., \& Entezari, M. H. (2008). Effect of fortification of defatted soy flour on sensory and rheological properties of wheat bread. International Journal of Food Science and Technology, 43, 1693-1698. http://dx.doi.org/10.1111/j.1365-2621.2008.01755.x

Mason, H., Navabi, A., Frick, B., O’Donovan, J., Niziol, D., \& Spaner, D. (2006). Does growing Canadian Western Hard Red Spring wheat under organic management alter its breadmaking quality? Renewable Agriculture and Food Systems, 22(3), 157-167. http://dx.doi.org/10.1017/S1742170507001688

Matsuo, R. R., Dexter, J. E., Kosmolak, F. G., \& Leisle, D. (1982). Statistical evaluation of tests for assessing spaghetti making quality of durum wheat. Cereal Chemistry, 59, 222-228.

Mercier, S., Villeneuve, S., Mondor, M., \& Des Marchais, L. P. (2011). Evolution of porosity, shrinkage and density of pasta fortified with pea protein isolate during drying, LWT - Food Science and Technology, 44, 883-890. http://dx.doi.org/10.1016/j.lwt.2010.11.032

Nielsen, M. A., Sumner, A. K., \& Whalley, L. L. (1980). Fortification of pasta with pea flour and air-classified pea protein concentrate. Cereal Chemistry, 57, 203-207.

Oak, M. D., Sissons, M., Egan, N., Tamhankar, S. A., Rao, V. S., \& Bhosale, S. B. (2006). Relationship between gluten strength and pasta firmness in Indian durum wheats. International Journal of Food Science \& Technology, 41, 538-544. http://dx.doi.org/10.1111/j.1365-2621.2005.01103.x

Ohm, J. B., \& Chung, O. K. (1999). Gluten, Pasting, and Mixograph Parameters of Hard Winter Wheat Flours in Relation to Breadmaking. Cereal Chemistry, 76, 606-613. http://dx.doi.org/10.1094/CCHEM.1999.76.5.606

Petitot, M., Boyer, L., Minier, C., \& Micard, V. (2010). Fortification of pasta with split pea and faba bean flours: Pasta processing and quality evaluation. Food Research International, 43(2), 634-641. http://dx.doi.org/10.1016/j.foodres.2009.07.020

Petruccelli, S., \& Anon M. C. (1994). Relationship between the method of obtention and structural and functional properties of soy protein isolates. 1. Structural and hydration properties. Journal of Agricultural and Food Chemistry, 42, 2161-2169. http://dx.doi.org/10.1021/jf00046a017

Rao, A., Shallo, H. E., Ericson, A. P., \& Thomas, R. L. (2002). Characterization of soy protein concentrate produced by membrane ultrafiltration. Journal of Food Science, 67(4), 1412-1418. http://dx.doi.org/10.1111/j.1365-2621.2002.tb10299.x

Ribotta, P. D., Edel Leon, A., Pérez, G.. T., \& Anon, M. C. (2005). Electrophoresis studies for determining wheat-soy protein interactions in dough and bread. European Food Research and Technology, 221, 48-53. http://dx.doi.org/10.1007/s00217-005-1135-2

Roccia, P., Ribotta, P. D., Pérez, G.. T., \& Leon, A. E. (2009). Influence of soy protein on rheological properties and water retention capacity of wheat gluten. LWT - Food Science and Technology, 42, $358-362$. http://dx.doi.org/10.1016/j.lwt.2008.03.002

Sabanis, D., Makri, E., \& Doxastakis, G. (2006). Effect of durum flour enrichment with chickpea flour on the characteristics of dough and lasagne. Journal of the Science of Food and Agriculture, 86, 1938-1944. http://dx.doi.org/10.1002/jsfa.2567

Sánchez-Lozano, N. B., \& Martínez-Llorens, S. (2009). Effect of high-level fish meal replacement by pea and 
rice concentrate protein on growth, nutrient utilization and fillet quality in gilthead seabream (Sparus aurata, L.). Aquaculture, 298, 83-89. http://dx.doi.org/doi:10.1016/j.aquaculture.2009.09.028

Shogren, R. L., Hareland, G. A., \& Wu, Y. V. (2006). Sensory Evaluation and Composition of Spaghetti Fortified with Soy Flour. Journal of Food Science, 71, S428-S432. http://dx.doi.org/10.1111/j.1750-3841.2006.00061.x

Taherian, A. R., Mondor, M., Labranche, J., Drolet, H., Ippersiel, D., \& Lamarche, F. (2011). Comparative study of functional properties of commercial and membrane processed yellow pea protein isolates. Food Research International, 44, 2505-2514. http://dx.doi.org/10.1016/j.foodres.2011.01.030

Torres, A., Frias, J., Granito, M., Guerra, M., \& Vidal-Valverde, C. (2007). Chemical, biological and sensory evaluation of pasta products supplemented with $\alpha$-galactoside free lupin flours. Journal of the Science of Food and Agriculture, 87, 74-81. http://dx.doi.org/10.1002/jsfa.2673

Wagner, J. R., Sorgentini D. A., \& Anon M. C. (2000). Relation between solubility and surface hydrophobicity as an indicator of modifications during preparation processes of commercial and laboratory-prepared soy protein isolates. Journal of Agricultural and Food Chemistry, 48, 3159-3165. http://dx.doi.org/10.1021/jf990823b

Wood, J. A. (2009). Texture, processing and organoleptic properties of chickpea-fortified spaghettie with insights to the underlying mechanisms of traditional durum pasta quality. Journal of Cereal Science, 49, 128-133. http://dx.doi.org/10.1016/j.jcs.2008.07.016

Yanez-Farias, G. A., Bernal-Aguilar, V., Ramirez-Rodriguez, L., \& Barron-Hoyos, J. M. (1999). Note. Fortification of some cereal foods with a chickpea protein concentrate. Food Science Technology International, 5(1), 89-93. http://dx.doi.org/10.1177/108201329900500109

Zhao, Y. H., Manthey, F. A., Chang, S. K. C., Hou, H. J., \& Yuan, S. H. (2005). Quality characteristics of Spaghetti as Affected by Green and yellow Pea, Lentil, and Chickpea Flours. Journal of Food Science,70, S371-S376. http://dx.doi.org/10.1111/j.1365-2621.2005.tb11458.x

Table 1. Mixing properties of control and enriched dough under continuous water addition Farinograph method

\begin{tabular}{|c|c|c|c|c|c|c|c|c|c|c|}
\hline \multirow[t]{2}{*}{ Parameters } & & \multirow[b]{2}{*}{ Control } & \multicolumn{4}{|c|}{ CPPI } & \multicolumn{4}{|c|}{ MTPPI } \\
\hline & & & $5 \%$ & $10 \%$ & $15 \%$ & Mean & $5 \%$ & $10 \%$ & $15 \%$ & Mean \\
\hline \multirow[t]{2}{*}{ MWCDF } & g-water & 0.54 & 0.51 & 0.51 & 0.51 & 0.51 & 0.42 & 0.38 & 0.37 & 0.39 \\
\hline & g-semolina ${ }^{-1}$ & \pm 0.00 & \pm 0.01 & \pm 0.03 & \pm 0.01 & \pm 0.02 & \pm 0.01 & \pm 0.02 & \pm 0.00 & \pm 0.03 \\
\hline \multirow[t]{2}{*}{ WCMT } & g-water & 0.76 & 0.76 & 0.79 & 0.76 & 0.77 & 0.65 & 0.62 & 0.62 & 0.63 \\
\hline & g- semolina ${ }^{-1}$ & \pm 0.02 & \pm 0.02 & \pm 0.03 & \pm 0.01 & \pm 0.03 & \pm 0.02 & \pm 0.01 & \pm 0.01 & \pm 0.02 \\
\hline \multirow[t]{2}{*}{ MT } & FU & 521 & 539 & 608 & 687 & 611 & 787 & $>950$ & $>950$ & $>896$ \\
\hline & & \pm 17 & \pm 49 & \pm 48 & \pm 100 & \pm 86 & \pm 63 & & & \\
\hline
\end{tabular}

Where MWCDF is the minimum water content for dough formation, WCMT is the water content at maximum torque and MT is the maximum torque.

Table 2. Gluten yield of control and enriched dough

\begin{tabular}{|c|c|c|c|c|c|c|c|c|c|c|}
\hline \multirow[t]{2}{*}{ Parameters } & & \multirow[b]{2}{*}{ Control } & \multicolumn{4}{|c|}{ CPPI } & \multicolumn{4}{|c|}{ MTPPI } \\
\hline & & & $5 \%$ & $10 \%$ & $15 \%$ & Mean* & $5 \%$ & $10 \%$ & $15 \%$ & Mean \\
\hline GI & $\%$ & $72.7 \pm 0.8$ & $71.8 \pm 0.4$ & $73.9 \pm 2.2$ & - & $72.9 \pm 1.3$ & $83.2 \pm 2.5$ & $85.1 \pm 1.9$ & $85.6 \pm 2.3$ & $84.7 \pm 0.3$ \\
\hline WG & $\%$ & $48.3 \pm 1.0$ & $49.1 \pm 0.6$ & $47.7 \pm 2.2$ & - & $48.4 \pm 1.1$ & $44.4 \pm 0.3$ & $44.4 \pm 0.5$ & $40.0 \pm 1.1$ & $43.0 \pm 0.3$ \\
\hline DG & $\%$ & $16.8 \pm 0.2$ & $16.9 \pm 0.3$ & $16.4 \pm 0.9$ & - & $16.6 \pm 0.4$ & $15.6 \pm 0.1$ & $15.4 \pm 0.1$ & $13.6 \pm 0.2$ & $14.8 \pm 0.1$ \\
\hline WBC & $\%$ & $65.1 \pm 1.1$ & $68.7 \pm 3.6$ & $65.7 \pm 0.3$ & - & $66.7 \pm 2.3$ & $64.7 \pm 0.7$ & $65.4 \pm 0.4$ & $65.9 \pm 0.6$ & $65.3 \pm 0.2$ \\
\hline
\end{tabular}

Where GI is the gluten index, WG is ratio of wet gluten to dry durum wheat semolina, DG is ratio of dry gluten to dry durum wheat semolina and WBC is the water binding capacity as \% of wet gluten.

* Mean value was calculated from 5 and $10 \%$ data since no data were available at $15 \%$. 

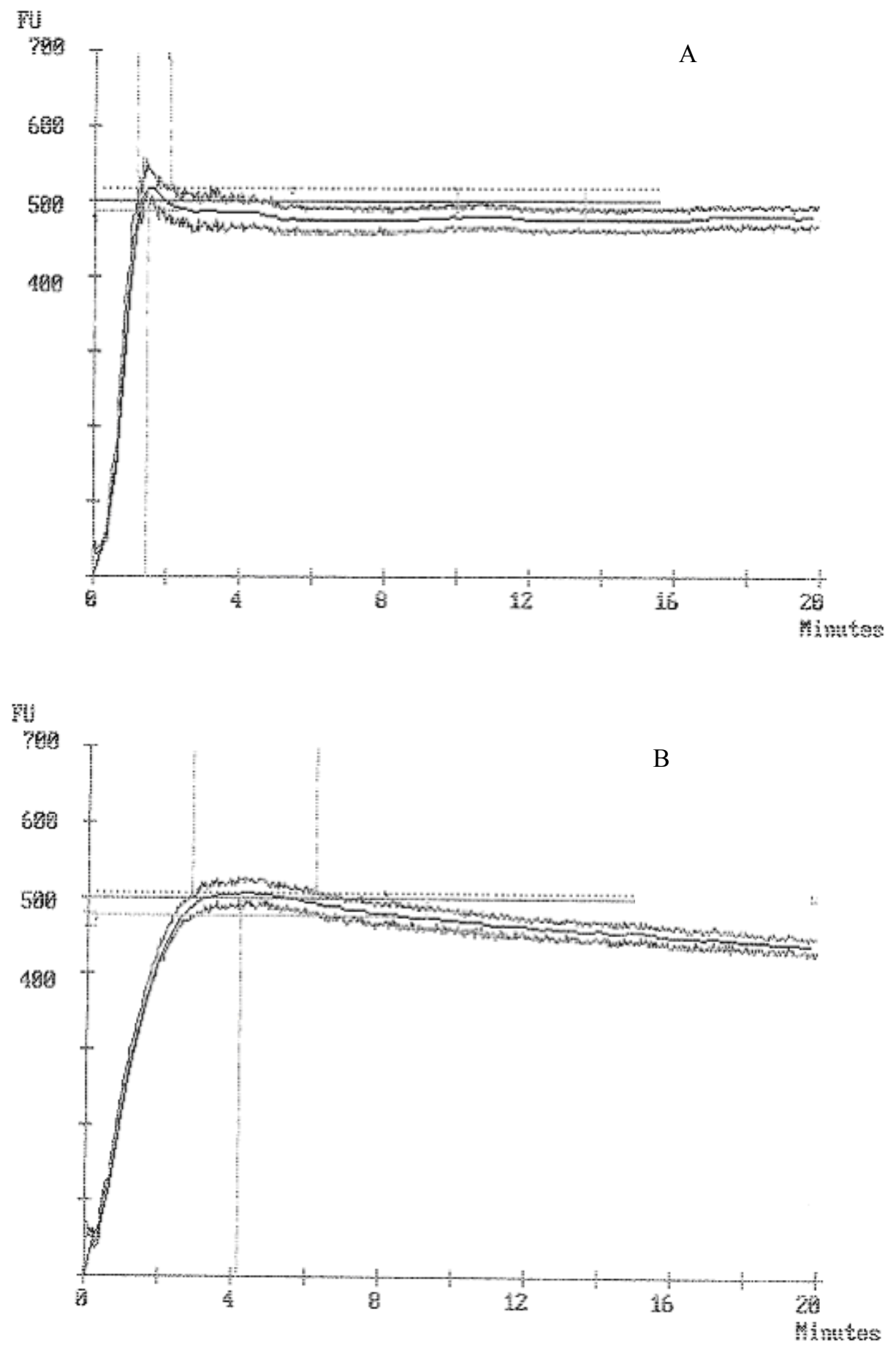

Figure 1. Typical experimental plot of resistance to mixing versus time for constant dough weigh Farinograph test with durum wheat semolina enriched with $10 \%$ CPPI (a) and MTPPI (b) 


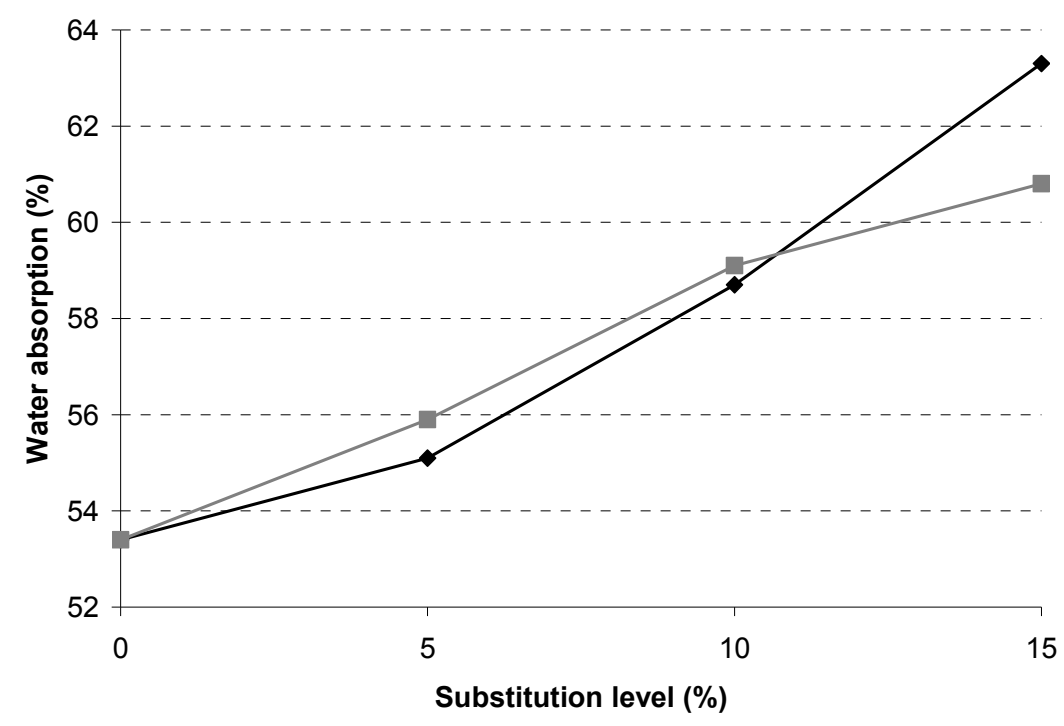

Figure 2. Experimental results of water absorption for Farinograph constant dough weight procedure with durum wheat semolina enriched with CPPI (black line) and MTPPI (grey line) at 0, 5, 10 and 15\% level

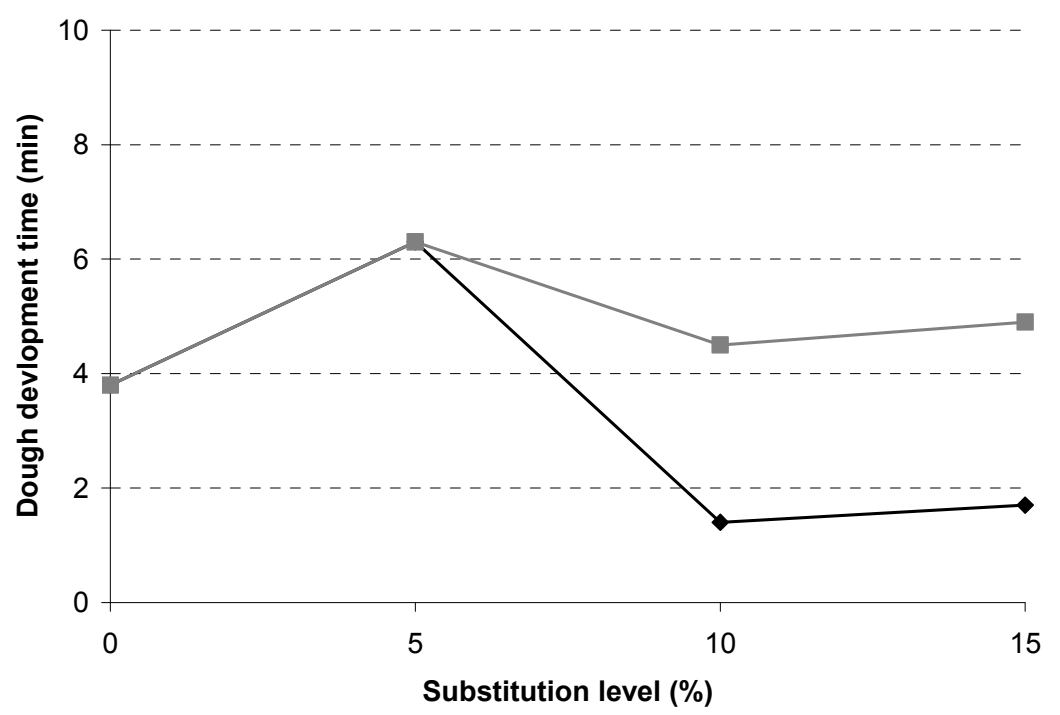

Figure 3. Experimental results of dough development time for Farinograph constant dough weight procedure with durum wheat semolina enriched with CPPI (black line) and MTPPI (grey line) at 0,5,10 and 15\% level 


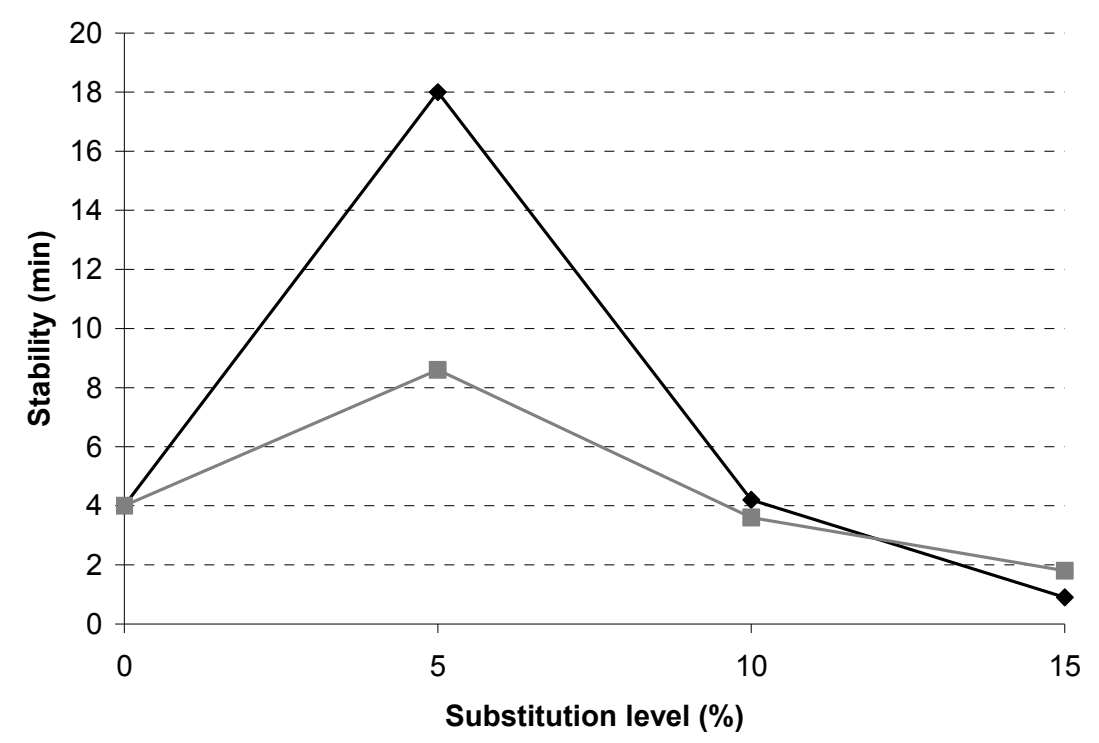

Figure 4. Experimental results stability for Farinograph constant dough weight procedure with durum wheat semolina enriched with CPPI (black line) and MTPPI (grey line) at 0, 5, 10 and 15\% level

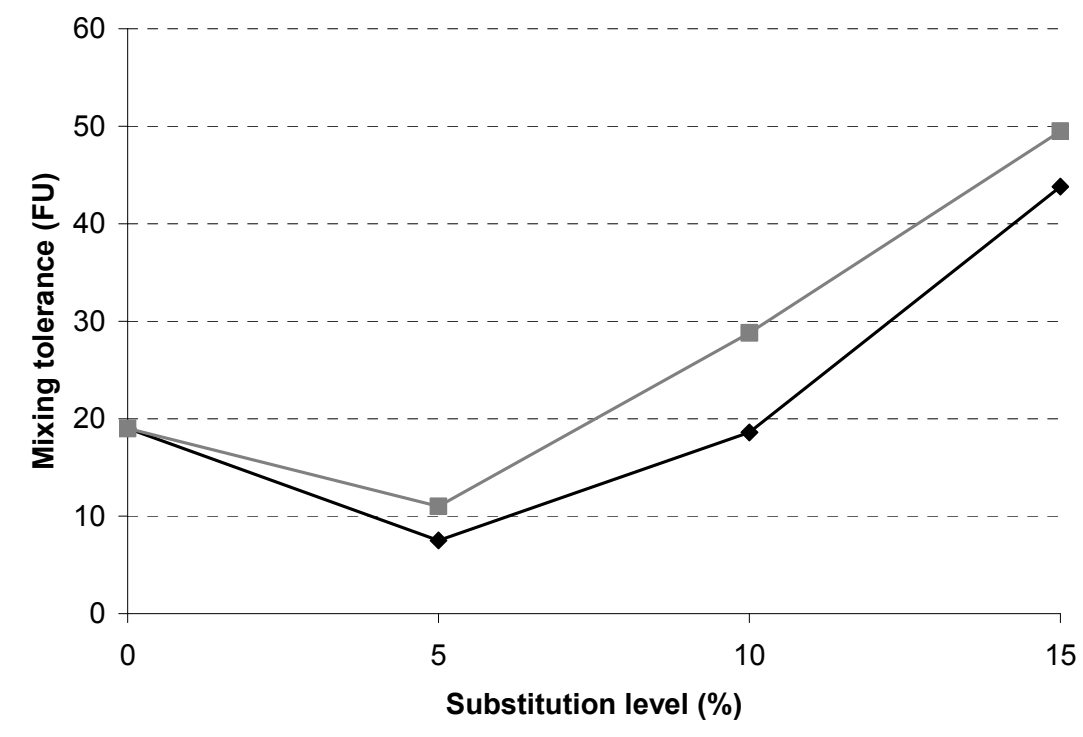

Figure 5. Experimental results of mixing tolerance index for Farinograph constant dough weight procedure with durum wheat semolina enriched with CPPI (black line) and MTPPI (grey line) at 0, 5, 10 and 15\% level 


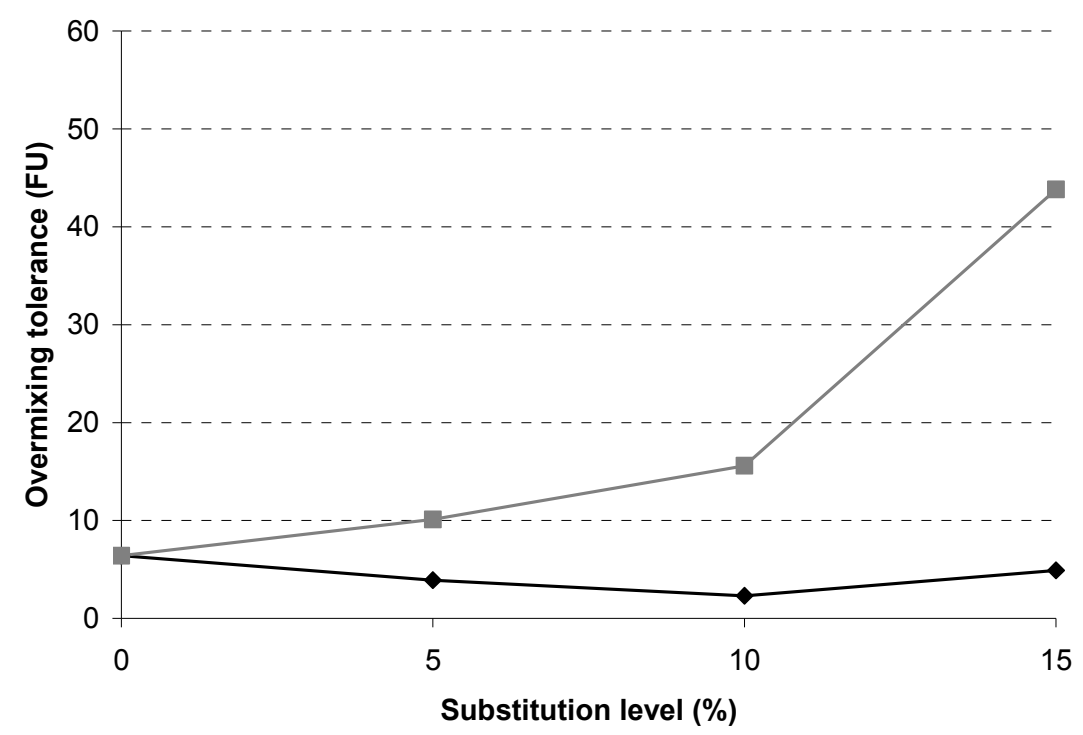

Figure 6. Experimental results of overmixing tolerance index for Farinograph constant dough weight procedure with durum wheat semolina enriched with CPPI (black line) and MTPPI (grey line) at 0,5, 10 and 15\% level

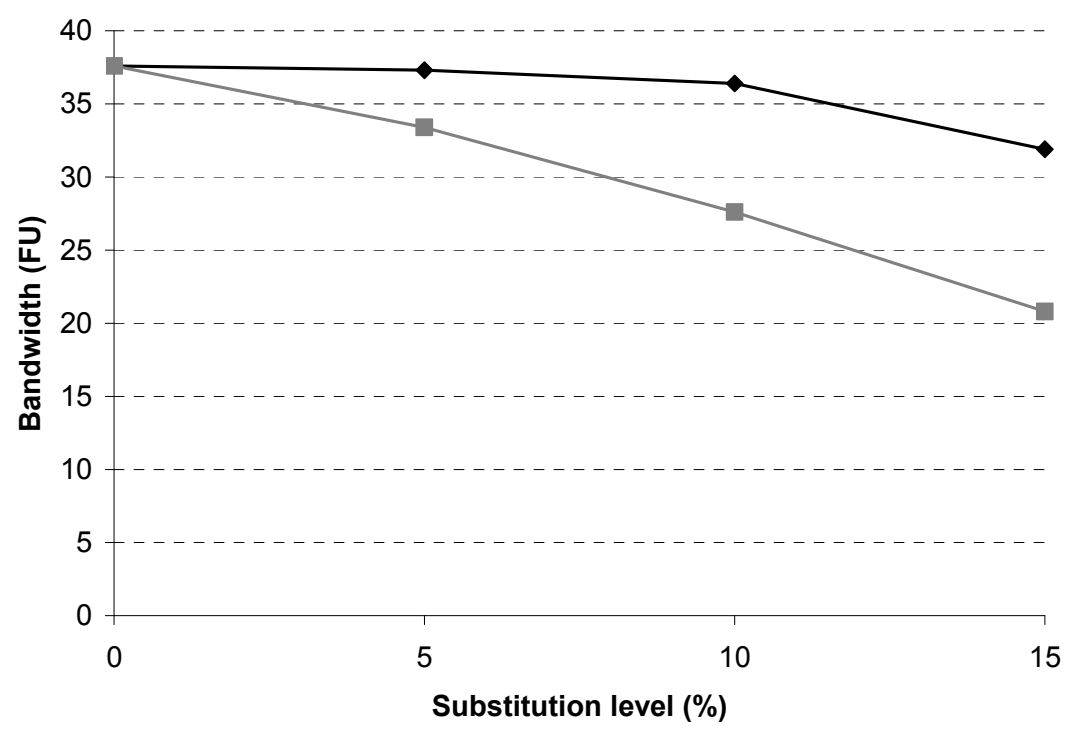

Figure 7. Experimental results of bandwidth for Farinograph constant dough weight procedure with durum wheat semolina enriched with CPPI (black line) and MTPPI (grey line) at 0, 5, 10 and $15 \%$ level 